\title{
A modified Mann iteration for zero points of accretive operators
}

\author{
Jianmin Song ${ }^{*}$ and Minjiang Chen
}

\author{
"Correspondence: \\ hbsongjm@yeah.net \\ Department of Mathematics and \\ Sciences, Shijiazhuang University of \\ Economics, Shijiazhuang, Hebe \\ 050031, China
}

\begin{abstract}
A modified Mann iteration with computational errors is investigated. A strong convergence theorem for zero points of an $m$-accretive operator is established in a Banach space.
\end{abstract}

MSC: 47H06; 47H09; 47J25; 65J15

Keywords: accretive operator; fixed point; nonexpansive mapping; zero point

\section{Introduction}

In this paper, we are concerned with the problem of finding zero points of accretive operators. Interest in accretive operators stems mainly from their firm connection with equations of evolution, and this is an important class of nonlinear operators. It is known that many physically significant problems can be modelled by initial value problems of the form

$$
x^{\prime}(t)+A x(t)=0, \quad x(0)=x_{0},
$$

where $A$ is an accretive operator in an appropriate Banach space. Typical examples where such evolution equations occur can be found in the heat, wave or Schrödinger equations. If $x(t)$ is dependent of $t$, then (1.1) is reduced to

$$
A u=0 \text {, }
$$

whose solutions correspond to the equilibrium points of (1.1). An early fundamental result in the theory of accretive operators, due to Browder [1], states that the initial value problem (1.1) is solvable if $A$ is locally Lipschitz and accretive on $E$. One of the most popular techniques for solving zero points of accretive operators goes back to the work of Browder [2]. One of the basic ideas in the case of a Hilbert space $H$ is reducing the above equation (1.2) to a fixed point problem of the operator $R_{A}: H \rightarrow 2^{H}$ defined by $R_{A}=(I+A)^{-1}$, which is called the classical resolvent of $A$.

The paper is organized in the following way. In Section 2, we present the preliminaries that are needed in our work. In Section 3, a modified Mann iteration with computational errors is presented. A strong convergence theorem for zero points of an $m$-accretive operator is established in a Banach space. In Section 4, applications of the main results are discussed.

○2013 Song and Chen; licensee Springer. This is an Open Access article distributed under the terms of the Creative Commons Attribution License (http://creativecommons.org/licenses/by/2.0), which permits unrestricted use, distribution, and reproduction in any medium, provided the original work is properly cited. 


\section{Preliminaries}

Let $E$ be a real Banach space $E$ and let $E^{*}$ be the dual space of $E$. Let $\langle\cdot, \cdot\rangle$ denote the pairing between $E$ and $E^{*}$. The normalized duality mapping $J: E \rightarrow 2^{E^{*}}$ is defined by

$$
J(x)=\left\{f \in E^{*}:\langle x, f\rangle=\|x\|^{2}=\|f\|^{2}\right\}
$$

for all $x \in E$. Let $U_{E}=\{x \in E:\|x\|=1\}$. $E$ is said to be smooth or is said to have a Gâteaux differentiable norm if the $\operatorname{limit} \lim _{t \rightarrow 0} \frac{\|x+t y\|-\|x\|}{t}$ exists for each $x, y \in U_{E}$. $E$ is said to have a uniformly Gâteaux differentiable norm if for each $y \in U_{E}$, the limit is attained uniformly for all $x \in U_{E}$. $E$ is said to be uniformly smooth or is said to have a uniformly Fréchet differentiable norm if the limit is attained uniformly for $x, y \in U_{E}$. In the sequel, we use $j$ to denote the single-valued normalized duality mapping. It is known that if the norm of $E$ is uniformly Gâteaux differentiable, then the duality mapping $J$ is single-valued and uniformly norm to weak* continuous on each bounded subset of $E$.

Recall that a closed convex subset $C$ of a Banach space $E$ is said to have the normal structure if for each bounded closed convex subset $K$ of $C$ which contains at least two points, there exists an element $x$ of $K$ which is not a diametral point of $K$, i.e., $\sup \{\|x-y\|$ : $y \in K\}<d(K)$, where $d(K)$ is the diameter of $K$. It is well known that a closed convex subset of a uniformly convex Banach space has the normal structure and a compact convex subset of a Banach space has the normal structure; see [3] for more details.

Let $T: C \rightarrow C$ be a mapping. Recall that $T$ is said to be contractive if there exits a constant $\alpha \in(0,1)$ such that

$$
\|T x-T y\| \leq \alpha\|x-y\|, \quad \forall x, y \in C .
$$

For such a case, we also call $T$ an $\alpha$-contraction. $T$ is said to be nonexpansive if

$$
\|T x-T y\| \leq\|x-y\|, \quad \forall x, y \in C .
$$

Let $D$ be a nonempty subset of $C$. Let $Q: C \rightarrow D$. $Q$ is said to be contraction if $Q^{2}=Q$; sunny if for each $x \in C$ and $t \in(0,1)$, we have $Q(t x+(1-t) Q x)=Q x$; sunny nonexpansive retraction if $Q$ is sunny, nonexpansive, and contraction. $K$ is said to be a nonexpansive retract of $C$ if there exists a nonexpansive retraction from $C$ onto $D$.

The following result, which was established in [4], describes a characterization of sunny nonexpansive retractions on a smooth Banach space.

Let $E$ be a smooth Banach space and $C$ be a nonempty subset of $E$. Let $Q: E \rightarrow C$ be a retraction and $j$ be the normalized duality mapping on $E$. Then the following are equivalent:

(1) $Q$ is sunny and nonexpansive;

(2) $\|Q x-Q y\|^{2} \leq\langle x-y, j(Q x-Q y)\rangle, \forall x, y \in E$;

(3) $\langle x-Q x, j(y-Q x)\rangle \leq 0, \forall x \in E, y \in C$.

Krasnoselski-Mann iteration generates a sequence $\left\{x_{n}\right\}$ in the following manner:

$$
x_{0} \in C, \quad x_{n+1}=\alpha_{n} T x_{n}+\left(1-\alpha_{n}\right) x_{n}, \quad \forall n \geq 0 .
$$

It is known that the Krasnoselski-Mann iteration only has weak convergence even for nonexpansive mappings in infinite-dimensional Hilbert spaces; for more details, see [5] 
and the references therein. In many disciplines, including economics, image recovery, quantum physics, and control theory, problems arise in infinite dimension spaces. In such problems, strong convergence (norm convergence) is often much more desirable than weak convergence, for it translates the physically tangible property that the energy $\left\|x_{n}-x\right\|$ of the error between the iterate $x_{n}$ and the solution $x$ eventually becomes arbitrarily small. To improve the weak convergence of Krasnoselski-Mann iterative process, different modified Mann iterations have been considered; see [6-30] and the references therein.

Let $I$ denote the identity operator on $E$. An operator $A \subset E \times E$ with domain $D(A)=\{z \in$ $E: A z \neq \emptyset\}$ and range $R(A)=\bigcup\{A z: z \in D(A)\}$ is said to be accretive if for each $x_{i} \in D(A)$ and $y_{i} \in A x_{i}, i=1,2$, there exists $j\left(x_{1}-x_{2}\right) \in J\left(x_{1}-x_{2}\right)$ such that $\left\langle y_{1}-y_{2}, j\left(x_{1}-x_{2}\right)\right\rangle \geq 0$. An accretive operator $A$ is said to be $m$-accretive if $R(I+r A)=E$ for all $r>0$. In a real Hilbert space, an operator $A$ is $m$-accretive if and only if $A$ is maximal monotone. In this paper, we use $A^{-1}(0)$ to denote the set of zeros of $A$.

For an accretive operator $A$, we can define a nonexpansive single-valued mapping $J_{r}$ : $R(I+r A) \rightarrow D(A)$ by $J_{r}=(I+r A)^{-1}$ for each $r>0$, which is called the resolvent of $A$.

One of classical methods of studying the problem $0 \in A x$, where $A \subset E \times E$ is an accretive operator, is the following:

$$
x_{0} \in E, \quad x_{n+1}=J_{r_{n}} x_{n}, \quad \forall n \geq 0,
$$

where $J_{r_{n}}=\left(I+r_{n} A\right)^{-1}$ and $\left\{r_{n}\right\}$ is a sequence of positive real numbers.

The following iteration also has been extensively investigated:

$$
x_{n+1}=\alpha_{n} u+\left(1-\alpha_{n}\right) J_{r_{n}} x_{n}, \quad \forall n \geq 0,
$$

where $\left\{\alpha_{n}\right\}$ is a real number sequence in $(0,1),\left\{r_{n}\right\}$ is a positive real number sequence, and $J_{r_{n}}=\left(I+r_{n} A\right)^{-1}$. It is known that the sequence $\left\{x_{n}\right\}$ generated in the above iteration converges strongly to a zero point of $A$ in a Banach space under some restrictions imposed on $\left\{\alpha_{n}\right\}$ and $\left\{r_{n}\right\}$.

Chen et al. [29] investigated the following iteration:

$$
\left\{\begin{array}{l}
y_{n}=\beta_{n} x_{n}+\left(1-\beta_{n}\right) J_{r_{n}} x_{n}, \\
x_{n+1}=\alpha_{n} f\left(x_{n}\right)+\left(1-\alpha_{n}\right) y_{n}, \quad \forall n \geq 0,
\end{array}\right.
$$

where $\left\{\alpha_{n}\right\}$ and $\left\{\beta_{n}\right\}$ are real number sequences in $(0,1),\left\{r_{n}\right\}$ is a positive real number sequence, and $J_{r_{n}}=\left(I+r_{n} A\right)^{-1}$. They proved that the sequence $\left\{x_{n}\right\}$ generated in the above iteration converges strongly to a zero point of $A$ in a Banach space; for more details, see [29] and the references therein.

We also remark that the viscosity approximation method was first introduced by Moudafi [31] in the framework of Hilbert spaces. Moudafi proved that the desired solution is not only a fixed point of nonlinear mappings but a solution to some variational inequality; for more details, see [31] and the references therein.

Recently, Qin et al. [20] investigated the iteration (2.4) with double computational errors and established a strong convergence theorem in a real reflexive Banach space with the uniformly Gâteaux differentiable norm; for more details, see [20] and the references therein. Different regularization methods recently have been investigated for treating zero 
points of accretive operators. In this paper, a modified Mann iteration with computational errors is investigated. A strong convergence theorem for zero points of an $m$-accretive operator is established in a Banach space. The results mainly improve the corresponding results in Qin and Su [6], Hao [15], Qin et al. [20] and Chen et al. [29].

In order to state our main results, we also need the following lemmas.

Lemma 2.1 [20] Let E be a real reflexive Banach space with the uniformly Gâteaux differentiable norm and the normal structure, and $C$ be a nonempty closed convex subset of $E$. Let $S: C \rightarrow C$ be a nonexpansive mapping with a fixed point, and $f: C \rightarrow C$ be a fixed contraction with the coefficient $\alpha \in(0,1)$. Let $\left\{x_{t}\right\}$ be a sequence generated by the following $x_{t}=t f\left(x_{t}\right)+(1-t) S x_{t}$, where $t \in(0,1)$. Then $\left\{x_{t}\right\}$ converges strongly as $t \rightarrow 0$ to a fixed point $x^{*}$ of $T$, which is the unique solution in $F(T)$ to the following variational inequality

$$
\left\langle f\left(x^{*}\right)-x^{*}, j\left(x^{*}-p\right)\right\rangle \geq 0, \quad \forall p \in F(S) .
$$

Lemma 2.2 [32] Let $\left\{x_{n}\right\}$ and $\left\{y_{n}\right\}$ be bounded sequences in a Banach space E, and $\left\{\beta_{n}\right\}$ be a sequence in $(0,1)$ with $0<\liminf _{n \rightarrow \infty} \beta_{n} \leq \limsup _{n \rightarrow \infty} \beta_{n}<1$. Suppose that $x_{n+1}=$ $\left(1-\beta_{n}\right) y_{n}+\beta_{n} x_{n}, \forall n \geq 1$ and

$$
\limsup _{n \rightarrow \infty}\left(\left\|y_{n+1}-y_{n}\right\|-\left\|x_{n+1}-x_{n}\right\|\right) \leq 0 .
$$

Then $\lim _{n \rightarrow \infty}\left\|y_{n}-x_{n}\right\|=0$.

Lemma 2.3 [33] Let $\left\{a_{n}\right\},\left\{b_{n}\right\}$, and $\left\{c_{n}\right\}$ be three nonnegative real sequences satisfying

$$
a_{n+1} \leq\left(1-t_{n}\right) a_{n}+b_{n}+c_{n}, \quad \forall n \geq 0,
$$

where $\left\{t_{n}\right\}$ is a sequence in $(0,1)$. Assume that the following conditions are satisfied:

(a) $\sum_{n=0}^{\infty} t_{n}=\infty$ and $b_{n}=o\left(t_{n}\right)$;

(b) $\sum_{n=0}^{\infty} c_{n}<\infty$.

Then $\lim _{n \rightarrow \infty} a_{n}=0$.

Lemma 2.4 [34] Let E be a Banach space and let $A$ be an m-accretive operator. For $\lambda>0$, $\mu>0$, and $x \in E$, we have $J_{\lambda} x=J_{\mu}\left(\frac{\mu}{\lambda} x+\left(1-\frac{\mu}{\lambda}\right) J_{\lambda} x\right)$, where $J_{\lambda}=(I+\lambda A)^{-1}$ and $J_{\mu}=(I+\mu A)^{-1}$.

\section{Main results}

Theorem 3.1 Let E be a real reflexive Banach space with the uniformly Gâteaux differentiable norm. Let $A$ be an m-accretive operator in $E$ such that $C:=\overline{D(A)}$ is convex and has the normal structure. Let $f: C \rightarrow C$ be an $\alpha$-contraction. Let $\left\{x_{n}\right\}$ be a sequence generated in the following manner: $x_{0} \in C$ and

$$
\left\{\begin{array}{l}
y_{n}=\beta_{n} x_{n}+\left(1-\beta_{n}\right) J_{r_{n}}\left(x_{n}+e_{n+1}\right), \\
x_{n+1}=\alpha_{n} f\left(x_{n}\right)+\left(1-\alpha_{n}\right) y_{n}, \quad \forall n \geq 0,
\end{array}\right.
$$

where $\left\{\alpha_{n}\right\}$ and $\left\{\beta_{n}\right\}$ are real number sequences in $(0,1),\left\{e_{n}\right\}$ is a sequence in $E,\left\{r_{n}\right\}$ is a positive real number sequence, and $J_{r_{n}}=\left(I+r_{n} A\right)^{-1}$. Assume that $A^{-1}(0)$ is not empty and the above control sequences satisfy the following restrictions: 
(a) $\lim _{n \rightarrow \infty} \alpha_{n}=0$ and $\sum_{n=1}^{\infty} \alpha_{n}=\infty$;

(b) $0<\liminf _{n \rightarrow \infty} \beta_{n} \leq \lim \sup _{n \rightarrow \infty} \beta_{n}<1$;

(c) $\sum_{n=1}^{\infty}\left\|e_{n}\right\|<\infty$;

(d) $r_{n} \geq r$ for each $n \geq 1$ and $\lim _{n \rightarrow \infty}\left|r_{n}-r_{n+1}\right|=0$.

Then the sequence $\left\{x_{n}\right\}$ converges strongly to $\bar{x}$, which is the unique solution to the following variational inequality $\langle f(\bar{x})-\bar{x}, j(p-\bar{x})\rangle \leq 0, \forall p \in A^{-1}(0)$.

Proof First, we prove that $\left\{x_{n}\right\}$ is bounded. Fixing $p \in A^{-1}(0)$, we see that

$$
\begin{aligned}
\left\|y_{n}-p\right\| & \leq \beta_{n}\left\|x_{n}-p\right\|+\left(1-\beta_{n}\right)\left\|J_{r_{n}}\left(x_{n}+e_{n+1}\right)-p\right\| \\
& \leq\left\|x_{n}-p\right\|+\left\|e_{n+1}\right\| .
\end{aligned}
$$

It follows that

$$
\begin{aligned}
\left\|x_{n+1}-p\right\| \leq & \alpha_{n}\left\|f\left(x_{n}\right)-p\right\|+\left(1-\alpha_{n}\right)\left\|y_{n}-p\right\| \\
\leq & \left(1-\alpha_{n}(1-\alpha)\right)\left\|x_{n}-p\right\|+\alpha_{n}\|f(p)-p\|+\left\|e_{n+1}\right\| \\
\leq & \max \left\{\left\|x_{n}-p\right\|, \frac{\|f(p)-p\|}{1-\alpha}\right\}+\left\|e_{n+1}\right\| \\
\leq & \max \left\{\left\|x_{n-1}-p\right\|, \frac{\|f(p)-p\|}{1-\alpha}\right\}+\left\|e_{n}\right\|+\left\|e_{n+1}\right\| \\
& \vdots \\
\leq & \max \left\{\left\|x_{0}-p\right\|, \frac{\|f(p)-p\|}{1-\alpha}\right\}+\sum_{i=0}^{\infty}\left\|e_{i}\right\|<\infty .
\end{aligned}
$$

This proves that the sequence $\left\{x_{n}\right\}$ is bounded. If $r_{n} \geq r_{n+1}$, we see from Lemma 2.4 that

$$
\begin{aligned}
& \left\|J_{r_{n}}\left(x_{n}+e_{n+1}\right)-J_{r_{n+1}}\left(x_{n+1}+e_{n+2}\right)\right\| \\
& \quad \leq\left\|\frac{r_{n}}{r_{n+1}}\left(x_{n}+e_{n+1}\right)+\left(1-\frac{r_{n}}{r_{n+1}}\right) J_{r_{n+1}}\left(x_{n}+e_{n+1}\right)-\left(x_{n+1}+e_{n+2}\right)\right\| \\
& \quad=\left\|\frac{r_{n}}{r_{n+1}}\left(\left(x_{n}+e_{n+1}\right)-\left(x_{n+1}+e_{n+2}\right)\right)+\frac{r_{n+1}-r_{n}}{r_{n+1}}\left(J_{r_{n+1}}\left(x_{n}+e_{n+1}\right)-\left(x_{n+1}+e_{n+2}\right)\right)\right\| \\
& \quad \leq\left\|x_{n}-x_{n+1}\right\|+\left\|e_{n+1}\right\|+\left\|e_{n+2}\right\|+\frac{M_{2}}{r}\left(r_{n}-r_{n+1}\right),
\end{aligned}
$$

where $M_{2}$ is an appropriate constant such that $M_{2} \geq \sup _{n \geq 1}\left\{\| J_{r_{n+1}}\left(x_{n}+e_{n+1}\right)-\left(x_{n+1}+\right.\right.$ $\left.\left.e_{n+2}\right) \|\right\}$. Put $z_{n}=\frac{x_{n+1}-\beta_{n} x_{n}}{1-\beta_{n}}$; that is,

$$
x_{n+1}=\left(1-\beta_{n}\right) z_{n}+\beta_{n} x_{n}, \quad n \geq 0 .
$$

Note that

$$
\begin{aligned}
z_{n+1}-z_{n}= & \frac{\alpha_{n+1} f\left(x_{n+1}\right)+\left(1-\alpha_{n+1}\right) y_{n+1}-\beta_{n+1} x_{n+1}}{1-\beta_{n+1}} \\
& -\frac{\alpha_{n} f\left(x_{n}\right)+\left(1-\alpha_{n}\right) y_{n}-\beta_{n} x_{n}}{1-\beta_{n}}
\end{aligned}
$$




$$
\begin{aligned}
= & \frac{\alpha_{n+1}}{1-\beta_{n+1}}\left(f\left(x_{n+1}\right)-y_{n+1}\right)+J_{r_{n+1}}\left(x_{n+1}+e_{n+2}\right)-\frac{\alpha_{n}}{1-\beta_{n}}\left(f\left(x_{n}\right)-y_{n}\right) \\
& -J_{r_{n}}\left(x_{n}+e_{n+1}\right) .
\end{aligned}
$$

It follows that

$$
\begin{aligned}
\left\|z_{n+1}-z_{n}\right\| \leq & \frac{\alpha_{n+1}}{1-\beta_{n+1}}\left\|f\left(x_{n+1}\right)-y_{n+1}\right\|+\frac{\alpha_{n}}{1-\beta_{n}}\left\|f\left(x_{n}\right)-y_{n}\right\| \\
& +\left\|J_{r_{n+1}}\left(x_{n+1}+e_{n+2}\right)-J_{r_{n}}\left(x_{n}+e_{n+1}\right)\right\| .
\end{aligned}
$$

Substituting (3.1) into (3.3), we arrive at

$$
\begin{aligned}
\left\|z_{n+1}-z_{n}\right\|-\left\|x_{n}-x_{n+1}\right\| \leq & \frac{\alpha_{n+1}}{1-\beta_{n+1}}\left\|f\left(x_{n+1}\right)-y_{n+1}\right\|+\frac{\alpha_{n}}{1-\beta_{n}}\left\|f\left(x_{n}\right)-y_{n}\right\| \\
& +\left\|e_{n+1}\right\|+\left\|e_{n+2}\right\|+\frac{M_{2}}{r}\left(r_{n}-r_{n+1}\right) .
\end{aligned}
$$

In view of restrictions (a), (b) and (c), we find that

$$
\limsup _{n \rightarrow \infty}\left(\left\|z_{n+1}-z_{n}\right\|-\left\|x_{n}-x_{n+1}\right\|\right) \leq 0 .
$$

By virtue of Lemma 2.2, one obtains that

$$
\lim _{n \rightarrow \infty}\left\|z_{n}-x_{n}\right\|=0 .
$$

It follows from (3.1) that $x_{n+1}-x_{n}=\left(1-\beta_{n}\right)\left(z_{n}-x_{n}\right)$. In view of restriction (c), we find from (3.4) that

$$
\lim _{n \rightarrow \infty}\left\|x_{n+1}-x_{n}\right\|=0 .
$$

If $r_{n} \leq r_{n+1}$, we can prove that (3.5) still holds. On the other hand, we have

$$
\begin{aligned}
& \left\|x_{n}-J_{r_{n}}\left(x_{n}+e_{n+1}\right)\right\| \\
& \quad \leq\left\|x_{n}-x_{n+1}\right\|+\left\|x_{n+1}-y_{n}\right\|+\left\|y_{n}-J_{r_{n}}\left(x_{n}+e_{n+1}\right)\right\| \\
& \quad \leq\left\|x_{n}-x_{n+1}\right\|+\alpha_{n}\left\|f\left(x_{n}\right)-y_{n}\right\|+\beta_{n}\left\|x_{n}-J_{r_{n}}\left(x_{n}+e_{n+1}\right)\right\| .
\end{aligned}
$$

It follows that

$$
\left(1-\beta_{n}\right)\left\|x_{n}-J_{r_{n}}\left(x_{n}+e_{n+1}\right)\right\| \leq\left\|x_{n}-x_{n+1}\right\|+\alpha_{n}\left\|f\left(x_{n}\right)-y_{n}\right\| .
$$

In view of restriction (b), one finds that

$$
\lim _{n \rightarrow \infty}\left\|x_{n}-J_{r_{n}}\left(x_{n}+e_{n+1}\right)\right\|=0 .
$$

Notice that

$$
\begin{aligned}
\left\|x_{n}-J_{r_{n}} x_{n}\right\| & \leq\left\|x_{n}-J_{r_{n}}\left(x_{n}+e_{n+1}\right)\right\|+\left\|J_{r_{n}}\left(x_{n}+e_{n+1}\right)-J_{r_{n}} x_{n}\right\| \\
& \leq\left\|x_{n}-J_{r_{n}}\left(x_{n}+e_{n+1}\right)\right\|+\left\|e_{n+1}\right\| .
\end{aligned}
$$


Since $\sum_{n=1}^{\infty}\left\|e_{n}\right\|<\infty$, from (3.6) we obtain that $\lim _{n \rightarrow \infty}\left\|x_{n}-J_{r_{n}} x_{n}\right\|=0$. Taking a fixed number $k$ such that $r>k>0$, we arrive at

$$
\begin{aligned}
\left\|J_{r_{n}} x_{n}-J_{k} x_{n}\right\| & =\left\|J_{k}\left(\frac{k}{r_{n}} x_{n}+\left(1-\frac{k}{r_{n}}\right) J_{r_{n}} x_{n}\right)-J_{k} x_{n}\right\| \\
& \leq\left|1-\frac{k}{r_{n}}\right|\left\|\left(J_{r_{n}} x_{n}-x_{n}\right)\right\| \\
& \leq\left\|J_{r_{n}} x_{n}-x_{n}\right\| .
\end{aligned}
$$

Since

$$
\left\|x_{n}-J_{k} x_{n}\right\| \leq\left\|x_{n}-J_{r_{n}} x_{n}\right\|+\left\|J_{r_{n}} x_{n}-J_{k} x_{n}\right\| \leq 2\left\|x_{n}-J_{r_{n}} x_{n}\right\|
$$

we therefore find that

$$
\lim _{n \rightarrow \infty}\left\|x_{n}-J_{k} x_{n}\right\|=0
$$

Now, we are in a position to prove that $\limsup _{n \rightarrow \infty}\left\langle\bar{x}-f(\bar{x}), j\left(x_{n}-\bar{x}\right)\right\rangle \leq 0$, where $\bar{x}=$ $\lim _{t \rightarrow 0} z_{t}$, and $z_{t}$ solves the fixed point equation

$$
z_{t}=t f\left(z_{t}\right)+(1-t) J_{k} z_{t}, \quad \forall t \in(0,1)
$$

Therefore, we see that

$$
\begin{aligned}
\left\|z_{t}-x_{n}\right\|^{2}= & (1-t)\left\langle J_{k} z_{t}-x_{n}, j\left(z_{t}-x_{n}\right)\right\rangle+t\left\langle f\left(z_{t}\right)-x_{n}, j\left(z_{t}-x_{n}\right)\right\rangle \\
= & (1-t)\left(\left\langle J_{k} z_{t}-J_{k} x_{n}, j\left(z_{t}-x_{n}\right)\right\rangle+\left\langle J_{k} x_{n}-x_{n}, j\left(z_{t}-x_{n}\right)\right\rangle\right) \\
& +t\left\langle f\left(z_{t}\right)-z_{t}, j\left(z_{t}-x_{n}\right)\right\rangle+t\left\langle z_{t}-x_{n}, j\left(z_{t}-x_{n}\right)\right\rangle \\
\leq & (1-t)\left(\left\|z_{t}-x_{n}\right\|^{2}+\left\|J_{k} x_{n}-x_{n}\right\|\left\|z_{t}-x_{n}\right\|\right) \\
& +t\left\langle f\left(z_{t}\right)-z_{t}, j\left(z_{t}-x_{n}\right)\right\rangle+t\left\|z_{t}-x_{n}\right\|^{2} \\
\leq & \left\|z_{t}-x_{n}\right\|^{2}+\left\|J_{k} x_{n}-x_{n}\right\|\left\|z_{t}-x_{n}\right\|+t\left\langle f\left(z_{t}\right)-z_{t}, j\left(z_{t}-x_{n}\right)\right\rangle, \quad \forall t \in(0,1) .
\end{aligned}
$$

This implies that

$$
\left\langle z_{t}-f\left(z_{t}\right), j\left(z_{t}-x_{n}\right)\right\rangle \leq \frac{1}{t}\left\|J_{k} x_{n}-x_{n}\right\|\left\|z_{t}-x_{n}\right\|, \quad \forall t \in(0,1) .
$$

It follows from (3.8) that

$$
\limsup _{n \rightarrow \infty}\left\langle z_{t}-f\left(z_{t}\right), j\left(z_{t}-x_{n}\right)\right\rangle \leq 0
$$

Since $z_{t} \rightarrow \bar{x}$ as $t \rightarrow 0$ and from the fact that $j$ is strong to weak* uniformly continuous on bounded subsets of $E$, we find that

$$
\begin{aligned}
& \left|\left\langle z_{t}-f\left(z_{t}\right), j\left(z_{t}-x_{n}\right)\right\rangle-\left\langle f(\bar{x})-\bar{x}, j\left(x_{n}-\bar{x}\right)\right\rangle\right| \\
& \quad \leq\left|\left\langle f(\bar{x})-\bar{x}, j\left(x_{n}-\bar{x}\right)\right\rangle-\left\langle f(\bar{x})-\bar{x}, j\left(x_{n}-z_{t}\right)\right\rangle\right|
\end{aligned}
$$




$$
\begin{aligned}
& +\left|\left\langle f(\bar{x})-\bar{x}, j\left(x_{n}-z_{t}\right)\right\rangle-\left\langle z_{t}-f\left(z_{t}\right), j\left(z_{t}-x_{n}\right)\right\rangle\right| \\
\leq & \left|\left\langle f(\bar{x})-\bar{x}, j\left(x_{n}-\bar{x}\right)-j\left(x_{n}-z_{t}\right)\right\rangle\right|+\left|\left\langle f(\bar{x})-\bar{x}+z_{t}-f\left(z_{t}\right), J\left(x_{n}-z_{t}\right)\right\rangle\right| \\
\leq & \|f(\bar{x})-\bar{x}\|\left\|j\left(x_{n}-\bar{x}\right)-j\left(x_{n}-z_{t}\right)\right\|+\left\|f(\bar{x})-\bar{x}+z_{t}-f\left(z_{t}\right)\right\|\left\|x_{n}-z_{t}\right\| .
\end{aligned}
$$

It follows that

$$
\lim _{t \rightarrow 0}\left|\left\langle z_{t}-f\left(z_{t}\right), j\left(z_{t}-x_{n}\right)\right\rangle-\left\langle f(\bar{x})-\bar{x}, j\left(x_{n}-\bar{x}\right)\right\rangle\right|=0 .
$$

For any $\epsilon>0$, there exists $\kappa>0$ such that $\forall t \in(0, \kappa)$ the following inequality holds

$$
\left\langle f(\bar{x})-\bar{x}, j\left(x_{n}-\bar{x}\right)\right\rangle \leq\left\langle z_{t}-f\left(z_{t}\right), j\left(z_{t}-x_{n}\right)\right\rangle+\epsilon .
$$

This implies that

$$
\limsup _{n \rightarrow \infty}\left\langle f(\bar{x})-\bar{x}, j\left(x_{n}-\bar{x}\right)\right\rangle \leq \limsup _{n \rightarrow \infty}\left\langle z_{t}-f\left(z_{t}\right), j\left(z_{t}-x_{n}\right)\right\rangle+\epsilon .
$$

Note that $\epsilon$ is arbitrary. In view of (3.9), we see that $\lim _{\sup _{n \rightarrow \infty}}\left\langle f(\bar{x})-\bar{x}, j\left(x_{n}-\bar{x}\right)\right\rangle \leq 0$. This implies that

$$
\limsup _{n \rightarrow \infty}\left\langle f(\bar{x})-\bar{x}, j\left(x_{n+1}-\bar{x}\right)\right\rangle \leq 0 \text {. }
$$

Finally, we show that $x_{n} \rightarrow \bar{x}$ as $n \rightarrow \infty$. Notice that

$$
\begin{aligned}
\left\|x_{n+1}-\bar{x}\right\|^{2} & \leq \alpha_{n}\left\langle f\left(x_{n}\right)-\bar{x}, j\left(x_{n+1}-\bar{x}\right)\right\rangle+\left(1-\alpha_{n}\right)\left\|y_{n}-\bar{x}\right\|\left\|x_{n+1}-\bar{x}\right\| \\
& \leq \alpha_{n}\left\{f\left(x_{n}\right)-\bar{x}, j\left(x_{n+1}-\bar{x}\right)\right\rangle+\frac{1-\alpha_{n}}{2}\left(\left\|y_{n}-\bar{x}\right\|^{2}+\left\|x_{n+1}-\bar{x}\right\|^{2}\right) .
\end{aligned}
$$

It follows that

$$
\left\|x_{n+1}-\bar{x}\right\|^{2} \leq\left(1-\alpha_{n}\right)\left\|x_{n}-\bar{x}\right\|^{2}+2 \alpha_{n}\left\langle f\left(x_{n}\right)-\bar{x}, j\left(x_{n+1}-\bar{x}\right)\right\rangle+d_{n}
$$

where $d_{n}=\left\|e_{n+1}\right\|\left(2\left\|x_{n}-\bar{x}\right\|+\left\|e_{n+1}\right\|\right)$. In view of restrictions (a) and (c), we know that $\sum_{n=1}^{\infty} d_{n}<\infty$. Put $a_{n}=\left\|x_{n}-\bar{x}\right\|^{2}, t_{n}=\alpha_{n}$, and $c_{n}=d_{n}$. In view of Lemma 2.3, we find the desired conclusion.

If $f(x)=u$, where $u$ is a fixed element in $C$, for any $x \in C$, we find the following result.

Corollary 3.2 Let E be a real reflexive Banach space with the uniformly Gâteaux differentiable norm. Let $A$ be an m-accretive operator in $E$ such that $C:=\overline{D(A)}$ is convex and has the normal structure. Let $\left\{x_{n}\right\}$ be a sequence generated in the following manner: $x_{0} \in C$ and

$$
\left\{\begin{array}{l}
y_{n}=\beta_{n} x_{n}+\left(1-\beta_{n}\right) J_{r_{n}} x_{n}, \\
x_{n+1}=\alpha_{n} u+\left(1-\alpha_{n}\right) y_{n}, \quad \forall n \geq 0,
\end{array}\right.
$$

where $\left\{\alpha_{n}\right\}$ and $\left\{\beta_{n}\right\}$ are real number sequences in $(0,1),\left\{r_{n}\right\}$ is a positive real number sequence, and $J_{r_{n}}=\left(I+r_{n} A\right)^{-1}$. Assume that $A^{-1}(0)$ is not empty and the above control sequences satisfy the following restrictions: 
(a) $\lim _{n \rightarrow \infty} \alpha_{n}=0$ and $\sum_{n=1}^{\infty} \alpha_{n}=\infty$;

(b) $0<\liminf _{n \rightarrow \infty} \beta_{n} \leq \limsup _{n \rightarrow \infty} \beta_{n}<1$;

(c) $r_{n} \geq$ r for each $n \geq 1$ and $\lim _{n \rightarrow \infty}\left|r_{n}-r_{n+1}\right|=0$.

Then the sequence $\left\{x_{n}\right\}$ converges strongly to $\bar{x}=Q_{A^{-1}(0)} u$.

\section{Applications}

In this section, we consider solutions of variational inequalities. Let $C$ be a nonempty, closed, and convex subset of a Banach space $E$. Let $A: C \rightarrow E^{*}$ be a single-valued monotone operator which is hemicontinuous; that is, continuous along each line segment in $C$ with respect to the weak ${ }^{*}$ topology of $E^{*}$. Consider the following variational inequality problem of finding a point $x \in C$ such that

$$
\langle y-x, A x\rangle \geq 0, \quad \forall y \in C .
$$

In this section, we use $\operatorname{VI}(C, A)$ to denote the solution set of the variational inequality involving $A$. The symbol $N_{C}(x)$ stands for the normal cone for $C$ at a point $x \in C$; that is,

$$
N_{C}(x)=\left\{x^{*} \in E^{*}:\left\langle y-x, x^{*}\right\rangle \leq 0, \forall y \in C\right\} .
$$

Theorem 4.1 Let E be a real reflexive Banach space with the uniformly Gâteaux differentiable norm. Let $C$ be a nonempty, closed, and convex subset of $E$. Let $A: C \rightarrow E^{*}$ be a single-valued, monotone, and hemicontinuous operator. Assume that $V I(C, A)$ is not empty and $C$ has the normal structure. Let $f: C \rightarrow C$ be an $\alpha$-contraction. Let $\left\{x_{n}\right\}$ be a sequence generated in the following manner: $x_{0} \in C$ and

$$
\left\{\begin{array}{l}
y_{n}=\beta_{n} x_{n}+\left(1-\beta_{n}\right) V I\left(C, A+\frac{1}{r_{n}}\left(I-x_{n}\right)\right), \\
x_{n+1}=\alpha_{n} f\left(x_{n}\right)+\left(1-\alpha_{n}\right) y_{n}, \quad \forall n \geq 0,
\end{array}\right.
$$

where $\left\{\alpha_{n}\right\}$ and $\left\{\beta_{n}\right\}$ are real number sequences in $(0,1),\left\{e_{n}\right\}$ is a sequence in $E,\left\{r_{n}\right\}$ is a positive real number sequence, and $J_{r_{n}}=\left(I+r_{n} A\right)^{-1}$. Assume that $A^{-1}(0)$ is not empty and the above control sequences satisfy the following restrictions:

(a) $\lim _{n \rightarrow \infty} \alpha_{n}=0$ and $\sum_{n=1}^{\infty} \alpha_{n}=\infty$;

(b) $0<\liminf _{n \rightarrow \infty} \beta_{n} \leq \limsup _{n \rightarrow \infty} \beta_{n}<1$;

(c) $r_{n} \geq r$ for each $n \geq 1$ and $\lim _{n \rightarrow \infty}\left|r_{n}-r_{n+1}\right|=0$.

Then the sequence $\left\{x_{n}\right\}$ converges strongly to $\bar{x}$, which is the unique solution to the following variational inequality $\langle f(\bar{x})-\bar{x}, j(p-\bar{x})\rangle \leq 0, \forall p \in A^{-1}(0)$.

Proof Define a mapping $T \subset E \times E^{*}$ by

$$
T x= \begin{cases}A x+N_{C} x, & x \in C, \\ \varnothing, & x \notin C .\end{cases}
$$

By Rockafellar [35], we know that $T$ is maximal monotone, and $T^{-1}(0)=V I(C, A)$. For each $r_{n}>0$ and $x_{n} \in E$, we see that there exists a unique $x_{r_{n}} \in D(T)$ such that $x_{n} \in x_{r}+r_{n} T\left(x_{r_{n}}\right)$, where $x_{r_{n}}=\left(I+r_{n} T\right)^{-1} x_{n}$. Notice that

$$
y_{n}=V I\left(C, A+\frac{1}{r_{n}}\left(I-x_{n}\right)\right),
$$


which is equivalent to

$$
\left\langle y-y_{n}, A y_{n}+\frac{1}{r_{n}}\left(y_{n}-x_{n}\right)\right\rangle \geq 0, \quad \forall y \in C,
$$

that is, $-A y_{n}+\frac{1}{r_{n}}\left(x_{n}-y_{n}\right) \in N_{C}\left(y_{n}\right)$. This implies that $y_{n}=\left(I+r_{n} T\right)^{-1} x_{n}$. Following the proof of Theorem 3.1, we can immediately conclude the desired conclusion.

If $f(x)=u$, where $u$ is a fixed element in $C$, for any $x \in C$, we find the following result.

Corollary 4.2 Let $E$ be a real reflexive Banach space with the uniformly Gâteaux differentiable norm. Let $C$ be a nonempty, closed, and convex subset of $E$. Let $A: C \rightarrow E^{*}$ be a single-valued, monotone, and hemicontinuous operator. Assume that VI $(C, A)$ is not empty and $C$ has the normal structure. Let $\left\{x_{n}\right\}$ be a sequence generated in the following manner: $x_{0} \in C$ and

$$
\left\{\begin{array}{l}
y_{n}=\beta_{n} x_{n}+\left(1-\beta_{n}\right) V I\left(C, A+\frac{1}{r_{n}}\left(I-x_{n}\right)\right), \\
x_{n+1}=\alpha_{n} u+\left(1-\alpha_{n}\right) y_{n}, \quad \forall n \geq 0,
\end{array}\right.
$$

where $\left\{\alpha_{n}\right\}$ and $\left\{\beta_{n}\right\}$ are real number sequences in $(0,1),\left\{e_{n}\right\}$ is a sequence in $E,\left\{r_{n}\right\}$ is a positive real number sequence, and $J_{r_{n}}=\left(I+r_{n} A\right)^{-1}$. Assume that $A^{-1}(0)$ is not empty and the above control sequences satisfy the following restrictions:

(a) $\lim _{n \rightarrow \infty} \alpha_{n}=0$ and $\sum_{n=1}^{\infty} \alpha_{n}=\infty$;

(b) $0<\liminf _{n \rightarrow \infty} \beta_{n} \leq \limsup _{n \rightarrow \infty} \beta_{n}<1$;

(c) $r_{n} \geq r$ for each $n \geq 1$ and $\lim _{n \rightarrow \infty}\left|r_{n}-r_{n+1}\right|=0$.

Then the sequence $\left\{x_{n}\right\}$ converges strongly to $\bar{x}=Q_{A^{-1}(0)} u$.

\section{Competing interests}

The authors declare that they have no competing interests.

\section{Authors' contributions}

All authors contributed equally to this manuscript. All authors read and approved the final manuscript.

\section{Acknowledgements}

This work is supported by the Department of Hebei Education (Z2013110). The authors are grateful to Professor Jin Wang and the anonymous reviewers for useful suggestions which improved the contents of the article.

Received: 1 October 2013 Accepted: 2 December 2013 Published: 19 Dec 2013

\section{References}

1. Browder, FE: Nonlinear mappings of nonexpansive and accretive type in Banach spaces. Bull. Am. Math. Soc. 73 875-882 (1967)

2. Browder, FE: Existence and approximation of solutions of nonlinear variational inequalities. Proc. Natl. Acad. Sci. USA 56, 1080-1086 (1966)

3. Takahashi, W: Nonlinear Functional Analysis: Fixed Point Theory and Its Application. Yokohama Publishers, Yokohama (2000)

4. Bruck, RE: Nonexpansive projections on subsets of Banach spaces. Pac. J. Math. 47, 341-355 (1973)

5. Genel, A, Lindenstrass, J: An example concerning fixed points. Isr. J. Math. 22, 81-86 (1975)

6. Qin, X, Su, Y: Approximation of a zero point of accretive operator in Banach spaces. J. Math. Anal. Appl. 329, 415-424 (2007)

7. Yang, S: Zero theorems of accretive operators in reflexive Banach spaces. J. Nonlinear Funct. Anal. 2013, Article ID 2 (2013)

8. Cho, SY, Kang, SM: Approximation of fixed points of pseudocontraction semigroups based on a viscosity iterative process. Appl. Math. Lett. 24, 224-228 (2011)

9. Cho, SY, Qin, X, Kang, SM: Iterative processes for common fixed points of two different families of mappings with applications. J. Glob. Optim. 57, 1429-1446 (2013) 
10. Yang, S: A proximal point algorithm for zeros of monotone operators. Math. Finance Lett. 2013, Article ID 7 (2013)

11. Zhang, H: Implicit iterative methods for zeros of accretive operators. J. Fixed Point Theory 2013, Article ID 2 (2013)

12. Song, J, Chen, M: On generalized asymptotically quasi- $\phi$-nonexpansive mappings and a Ky Fan inequality. Fixed Point Theory Appl. 2013, Article ID 237 (2013)

13. Cho, SY, Qin, X, Kang, SM: Hybrid projection algorithms for treating common fixed points of a family of demicontinuous pseudocontractions. Appl. Math. Lett. 25, 854-857 (2012)

14. Wu, C, Lv, S: Bregman projection methods for zeros of monotone operators. J. Fixed Point Theory 2013, Article ID 7 (2013)

15. Hao, Y: Zero theorems of accretive operators. Bull. Malays. Math. Sci. Soc. 34, 103-112 (2011)

16. Zegeye, $\mathrm{H}$, Shahzad, $\mathrm{N}$ : Strong convergence theorem for a common point of solution of variational inequality and fixed point problem. Adv. Fixed Point Theory 2, 374-397 (2012)

17. Cho, SY, Li, W, Kang, SM: Convergence analysis of an iterative algorithm for monotone operators. J. Inequal. Appl. 2013, Article ID 199 (2013)

18. Wang, ZM, Lou, W: A new iterative algorithm of common solutions to quasi-variational inclusion and fixed point problems. J. Math. Comput. Sci. 3, 57-72 (2013)

19. Wang, G, Sun, S: Hybrid projection algorithms for fixed point and equilibrium problems in a Banach space. Adv. Fixed Point Theory 3, 578-594 (2013)

20. Qin, $X$, Cho, SY, Wang, L: Iterative algorithms with errors for zero points of $m$-accretive operators. Fixed Point Theory Appl. 2013, Article ID 148 (2013)

21. Wu, C: Viscosity iterative algorithms for variational inequality. Adv. Inequal. Appl. 2014, Article ID 8 (2014)

22. Wu, C, Wang, G: Hybrid projection algorithms for asymptotically quasi- $\boldsymbol{\phi}$-nonexpansive mappings. Commun. Optim. Theory 2013, Article ID 2 (2013)

23. Kim, JK: Strong convergence theorems by hybrid projection methods for equilibrium problems and fixed point problems of the asymptotically quasi- $\phi$-nonexpansive mappings. Fixed Point Theory Appl. 2011, Article ID 10 (2011)

24. Qin, X, Cho, SY, Kim, JK: Convergence theorems on asymptotically pseudocontractive mappings in the intermediate sense. Fixed Point Theory Appl. 2010, Article ID 186874 (2010)

25. Lv, S, Wu, C: Convergence of iterative algorithms for a generalized variational inequality and a nonexpansive mapping. Eng. Math. Lett. 1, 44-57 (2012)

26. Cho, SY, Kang, SM: Approximation of common solutions of variational inequalities via strict pseudocontractions. Acta Math. Sci. 32, 1607-1618 (2012)

27. Qin, X, Su, Y: Strong convergence theorems for relatively nonexpansive mappings in a Banach space. Nonlinear Anal. 67, 1958-1965 (2007)

28. Zhu, ZJ: Strong convergence theorems for fixed points of nonlinear mappings. Eng. Math. Lett. 2014, Article ID 3 (2014)

29. Chen, R, Liu, Y, Shen, X: Iterative approximation of a zero of accretive operator in Banach space. Nonlinear Anal. 71 , e346-e350 (2009)

30. Qin, $X, C h o, Y J$, Kang, SM: Convergence theorems of common elements for equilibrium problems and fixed point problems in Banach spaces. J. Comput. Appl. Math. 225, 20-30 (2009)

31. Moudafi, A: Viscosity approximation methods for fixed-points problems. J. Math. Anal. Appl. 241, 46-55 (2000)

32. Suzuki, T: Strong convergence of Krasnoselskii and Mann's type sequences for one-parameter nonexpansive semigroups without Bochne integrals. J. Math. Anal. Appl. 305, 227-239 (2005)

33. Liu, L: Ishikawa-type and Mann-type iterative processes with errors for constructing solutions of nonlinear equations involving $m$-accretive operators in Banach spaces. Nonlinear Anal. 34, 307-317 (1998)

34. Barbu, V: Nonlinear Semigroups and Differential Equations in Banach Space. Noordhoff, Groningen (1976)

35. Rockafellar, TT: On the maximality of sums of nonlinear monotone operators. Trans. Am. Math. Soc. 149, 75-88 (1970)

10.1186/1687-1812-2013-347

Cite this article as: Song and Chen: A modified Mann iteration for zero points of accretive operators. Fixed Point Theory and Applications 2013, 2013:347

\section{Submit your manuscript to a SpringerOpen ${ }^{\circ}$ journal and benefit from:}

- Convenient online submission

- Rigorous peer review

- Immediate publication on acceptance

- Open access: articles freely available online

- High visibility within the field

- Retaining the copyright to your article 